\title{
Electrochemical Preparation of Molybdenum Coatings on Nickel from KF-MoO 3 Melts
}

\author{
Weiliang Jin ${ }^{1,2}$, Chuntao Ge $e^{1,2}$, Qian Kou ${ }^{1,2}$, Pengfei Jiang ${ }^{1}$, Saijun Xiao ${ }^{1,2, *}$ \\ ${ }^{1}$ School of Metallurgy Engineering, Anhui University of Technology, Maanshan, Anhui, China, \\ 243002 \\ ${ }^{2}$ Key Laboratory of Metallurgical Emission Reduction \& Resources Recycling, Anhui \\ University of Technology, Maanshan, Anhui, China, 243002 \\ *E-mail: xiaosaijunzj@yahoo.com
}

doi: $10.20964 / 2021.03 .30$

Received: 9 October 2020 / Accepted: 15 December 2020 / Published: 31 January 2021

In this paper, a molybdenum coating was first prepared in a molten $\mathrm{KF}-\mathrm{MoO}_{3}$ system by electrolysis, and the electrochemical behaviour of molybdenum ions in this system was studied at $900{ }^{\circ} \mathrm{C}$. In the electrochemical test, a platinum wire was used as the working electrode, a molybdenum wire was used as the quasi-reference electrode and a graphite crucible was used as the auxiliary electrode. Results showed that the reduction process of molybdenum ions on a platinum electrode was a one-step process with an exchange of six electrons. The cathode process was a quasi-reversible process controlled by diffusion, and the diffusion coefficient was calculated to be $0.905 \times 10^{-5} \mathrm{~cm}^{2} \cdot \mathrm{s}^{-1}$. Subsequently,

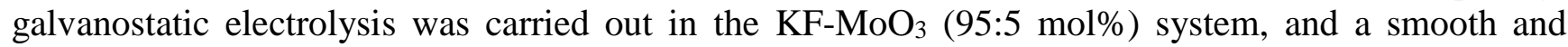
compact molybdenum coating was obtained. The influence of different electrolysis conditions on the quality of the molybdenum coating was also investigated. It is concluded that the coating quality was the best when the temperature was $900{ }^{\circ} \mathrm{C}$, the current density was $11-33 \mathrm{~mA} \cdot \mathrm{cm}^{-2}$, the electrolytic time was 30-60 minutes, and the base material was nickel.

Keywords: molybdenum coating; electrodeposition; molten salt; fluoride

\section{$\underline{\text { FULL TEXT }}$}

(C) 2021 The Authors. Published by ESG (www.electrochemsci.org). This article is an open access article distributed under the terms and conditions of the Creative Commons Attribution license (http://creativecommons.org/licenses/by/4.0/). 